\title{
MULTIPLE SOLUTIONS FOR A FOURTH ORDER EQUATION WITH NONLINEAR BOUNDARY CONDITIONS: THEORETICAL AND NUMERICAL ASPECTS
}

\author{
Cristiane Aparecida Pendeza Martinez, André Luís Machado \\ Martinez, Glaucia Maria Bressan, Emerson Vitor Castelani and \\ ROBERTO MOLINA DE SOUZA
}

Abstract. We consider in this work the fourth order equation with nonlinear boundary conditions. We present the result for the existence of multiple solutions based on the Avery-Peterson fixed-point theorem. This work is also a study for numerical solutions based on the LevenbergMaquardt method with a heuristic strategy for initial points that proposes to numerically determine multiple solutions to the problem addressed.

Mathematics subject classification (2010): 34-XX, 34-BXX, 34-B15.

Keywords and phrases: Multiple solution, Kirchhoff, fourth order equation, numerical solutions.

\section{REFERENCES}

[1] Friedman, Avner, Partial Differential Equations of Parabolic Type, Robert E. Krieger Publishing Company, Malabar, Florida, 1983.

[2] R. P. Agarwal, D. O'Regan and P. J. Y. Wong, Positive Solutions of Difierential, Difierence and Integral Equations, Kluwer, Dordrech, 1999.

[3] Krasnoselskit, M. A., Positive solutions of operator equations, Noordhoff, Groningen, 1964.

[4] A. Arosio, A geometrical nonlinear correction to the Timoshenko beam equation, Nonlinear Analysis 47 (2001) 729-740.

[5] R. I. AVERy AND A. C. Peterson, Three positive flxed points of nonlinear operators in ordered Banach spaces, Computers and Mathematics with Applications 42 (2001) 313-322.

[6] G. KirchHofi, Vorlessunger über Mathematiche Physik: Mechanik, Teubner, Leipzig, 1876.

[7] T. F. MA, Existence results and numerical solutions for a beam equation with nonlinear boundary conditions, Appl. Numer. Math. 47 (2003) 189-196.

[8] S. WOINOWSKY-KRIEGER, The efiect of axial force on the vibration of hinged bars, Journal of Applied Mechanics 17 (1950), 35-36.

[9] M. A. Del Pino AND R. F. MANaSevich, Existence for a fourth-order boundary value problem under a two-parameter nonresonance condition, Proc. American Math. Soc. 112 (1991) 81-86.

[10] T. F. MA, Existence results for a model of nonlinear beam on elastic bearings, Appl. Math. Lett. 13 (2000) 11-15.

[11] A. L. M. Martinez, E. V. Castelani, J. Silva, W. V. I. Shirabayashi, a note about positive solutions for an equation of Kirchhoff type, Applied Mathematics and Computation, Volume 218, Issue 5, 2011, Pages 2082-2090.

[12] T. F. MA, A. L. M. MARTINEZ, Positive solutions for a fourth order equation with nonlinear boundary conditions, Mathematics and Computers in Simulation, Volume 80, Issue 11, 2010, Pages 2177 2184.

[13] Y. WEI, Q. SONG, Z. BAI, Existence and iterative method for some fourth order nonlinear boundary value problems, Applied Mathematics Letters, Volume 87, 2019, Pages 101-107. 
[14] E. Alves, T. F. MA, M. L. Pelicer, Monotone positive solutions for a fourth order equation with nonlinear boundary conditions, Nonlinear Analysis: Theory, Methods and Applications, Volume 71, Issue 9, 2009, Pages 3834-3841.

[15] Jorge Nocedal and Stephen J. Wright, Numerical Optimization, Springer, 2006. 